\title{
К ВОПРОСУ О БАРЬЕРНЫХ КАЧЕСТВАХ ПЕСКОВ СЕВЕРНОГО И ЦЕНТРАЛЬНОГО ВЬЕТНАМА. СОРБЦИЯ ИОНОВ ЖЕЛЕЗА (II)
}

\author{
А.А. Яковлева, Ч. Т. Нгуен \\ АРИАДНА АЛЕКСЕЕВНА ЯКОВЛЕВА - доктор технических наук, профессор кафедрь «Химии и пищевой \\ технологии им. профессора В.В. Тутуриной» Иркутского национального исследовательского технического \\ университета. Область научных интересов: физико-химические закономерности протекания технологи- \\ ческих процессов, макрокинетика и явления переноса в дисперсных cucmeмax. E-mail: ayakovistu@mail.ru.
}

ЧУНГ ТХУЙ НГУЕН - аспирант кафедры «Химии и пищевой технологии им. профессора В.В. Тутуриной» Иркутского национального исследовательского технического университета.

E-mail:nguyentrungthuy_irk@mail.ru.

Иркутский наџиональный исследовательский технический университет, ул. Лермонтова, 83, г. Иркутск, Российская Федераџия, 664074.

Присутствующее в промышленных и бытовых стоках растворенное железо оказывает неблагоприятное воздействие на биоту прибрежных зон. Для оценивания барьерных качеств песков Вьетнама по отношению к ионам железа (III) рассмотрены 4 образца речных песков и один образец морского песка. Пески отобраны по берегам реки Хонга (вблизи Ханоя), а также рек Тхубон, Тхачхан и Кон северной и цеентральной провинций страны. Природная способность песков сорбировать ионь железа (III) обусловлена гранулометрическими соотношениями, геолого-минералогическим составом и некоторыми физико-химическими свойствами песчаных суспензий. Эксперименты проведены в модельных условиях, имитируюших контакт раствора железа (III) со слоем песка в динамических условиях.

Показано, что в условиях принудительной фильтрации повыпение ее скорости приводит к вымыванию сорбированных ионов с поверхности частии песка. Анализ результатов фильтрации свидетельствует, что барьерные качества прибрежных песков Северного и Центрального Вьетнама по отношению к ионам железа (III) различны. Отличия в структуре и минеральном составе позволили выделить три условные группы - чистый квариевый песок (морской), пески кремне-глиноземистые и полиминеральные пески. Такому делению симбатна сорбционная способность песков по отночению ионам Fе(III). Морской квариевый песок с минимальным количеством примесей обладает наилучшими сорбирующими качествами и может удерживать свыше 0,4 мг-ионов железа на один грамм поглотителя, что несопоставимо больше в сравнении с остальными песками. Появление в составе песка оксида алюминия приводит к снижению удерживающей способности. Полиминеральные пески характеризуются самыми низкими показателями в диапазоне 0,1-0,25 мг/2 ионов железа.

Ключевые слова: песок, минеральный состав, фильтрация, сорбция, промышленные стоки, ионы железа (III). 


\title{
TO THE QUESTION OF THE BARRIER QUALITIES OF THE SANDS OF NORTHERN AND CENTRAL VIETNAM. SORPTION OF IRON (III) IONS
}

\author{
A. A. Yakovleva, T. T. Nguyen \\ Irkutsk of National Technical University, 83 Lermontov Str., Irkutsk, 664074, Russian Federation.
}

\begin{abstract}
Dissolved iron present in industrial and domestic wastewater has an adverse effect on the biota of coastal zones. 4 samples of river sands and one sample of sea sand were considered to assess the barrier properties of Vietnam's sands in relation to iron (III) ions. The sands were selected along the banks of the Hong river (near Hanoi), as well as the Thu Bon, Thach Han and Kon rivers of the Northern and Central provinces of the country. The natural ability of sands to sorb iron (III) ions is due to the granulometric ratios, geological and mineralogical composition and some physical and chemical properties of sand suspensions. The experiments were performed under model conditions simulating the contact of an iron (III) solution with a sand layer under dynamic conditions.

It is shown that under conditions of forced filtration, an increase in its speed leads to the leaching of sorbed ions from the surface of sand particles. Analysis of filtration results shows that the barrier qualities of coastal sands of Northern and Central Vietnam in relation to iron (III) ions are different. Differences in the structure and mineral composition allowed us to distinguish three conditional groups-pure quartz sand (marine), silica-alumina sand and polymineral sand. The sorption capacity of the sands with respect to $\mathrm{Fe}$ (III) ions is similar to this division. Marine quartz sand with a minimum amount of impurities has the best sorbing qualities and can hold more than 0,4 mgiron ions per gram of the absorber, which is incomparably more in comparison with other sands. The appearance of aluminum oxide in the composition of the sand leads to a decrease in the holding capacity. Polymineral sands are characterized by the lowest values in the range of 0,1-0,25 $\mathrm{mg} / \mathrm{g}$ of iron ions.
\end{abstract}

Keywords: sand, mineral composition, filtration, sorption, industrial effluents, iron (III) ion.

\section{Введение}

Изучение поверхностных явлений в песках, как правило, не является самоцелью и связано с их предназначенностью $[1,2]$. Песок не только дешёвое минеральное сырье, он продолжает оставаться частью окружающей нас природы и определяет экологическую ситуацию местности.

Вопросы сохранности природных систем, в частности берегов водоемов значимы практически для всех стран. Во Вьетнаме исторически сложилось так, что из-за преимуществ водного транспорта многие индустриальные центры расположены по берегам рек. Развитие туризма приводит к обострению ситуации, связанной с сохранностью прибрежных зон. Зачастую пески принимают на себя функцию барьеров на пути проникновения различных агрессивных стоков в нижележащие слои почвы и биоту и определяют способность экосистемы к сохранению своего стабильного состояния [37].

Очевидно, что барьерные качества песка и их способность к самовосстановлению зависят как от- природных свойств, так и от уровня техногенной нагрузки.Изучение закономерностей фильтрования тех или иных стоков через слои песка позволяет оценить вклад различных механизмов загрязнения природной системы. В проведенном нами эксперименте имитируется фильтрование раствора железа (III) через слой песка в предположении, что удерживание железа обеспечено процессами сорбции. Мы акцентируем внимание на железе, потому что его избыточное количество является нежелательным: в речной или морской воде оно активизирует эрозию береговых линий и коррозию днищ водного транспорта [8], а в питьевой воде регламентировано СанПиН [9]. В качестве объектов исследования использованы пески Северного и Центрального Вьетнама. Подробная характеристика песков представлена ранее [10]. В данном исследовании кроме того использован песок Ж, по составу близкий песку А.

Цель исследования - изучить сорбцию ионов железа (III) на прибрежных песках Северного и Центрального Вьетнама и оценить их барьерные качества. 


\section{Методика эксперимента}

Коллоидно-химические исследования проводили с использованием общепринятых методик [11-13]. Навеску песка массой 3,00 г помещали в цилиндрическую емкость, сверху заливали 25 мл раствора хлорида железа (III) и собирали фильтрат, используя откалиброванный кран-регулятор снизу. Раствор готовили из навески 0,24 г железа (III) хлорида гексагидрата (соль марки ч) в 0,5 л дистиллированной воды, используя калиброванную посуду. Суммарная погрешность, учитывающая ошибки взвешивания и т. п., не превышала 2,5\%.

Концентрацию ионов железа (III) определяли фотометрическим методом [14]. Достоверность результатов при измерениях оптической плотности на КФК-3-01 обеспечена 3-х кратным фотометрированием проб с целью исключения случайных результатов и усреднения данных.

Количество адсорбированного железа рассчитывали по разности между начальной концентрацией раствора и концентрацией раствора после пропускания через песок :

$$
A=\frac{C_{0}-C}{m} \cdot V,
$$

где $m$ - масса навески песка; $V$ - объём раствора.

При адсорбционных исследованиях проводили параллельные опыты, используяприемы рандомизации, и анализировали средние арифметические значения результатов параллельных опытов.

\section{Результаты и их обсуждение}

Исходя из минерального состава, среди исследуемых песков можно выделить три существенно отличающиеся группы:

- 1 группа: кварцевый, мономинеральный песок $\Gamma$;

- 2 группа: в песках Б и К кроме $\alpha-\mathrm{SiO}_{2}$ содержится до $10-11 \% \alpha-\mathrm{Al}_{2} \mathrm{O}_{3}$;

- 3 группа: пески А и Ж полиминеральны, в них отсутствует корунд, содержание кварца близко, но не является доминирующим (табл. 1).

Изменения заряда поверхности минералов происходят закономерно по группам: у активной поверхности кварцевого песка значение $\zeta$-потенциала максимально и затем уменьшается при появлении в песках 2 группы корунда и других минералов в 3 группе.

На показатели сорбции влияют гидродинамические условия фильтрования - скорость потока и пористость песка (рис. 1 и 2).
Таблииа 1

Некоторые свойства песков

\begin{tabular}{|c|c|c|c|c|}
\hline \multirow{2}{*}{ Пески } & \multirow{2}{*}{$\zeta, \mathbf{M B}$} & \multicolumn{3}{|c|}{$\begin{array}{c}\text { Содержание минералов, } \\
\text { \%(масс.) }\end{array}$} \\
\hline & & $\alpha-\mathrm{SiO}_{2}$ & $\alpha-\mathrm{Al}_{2} \mathbf{O}_{3}$ & Прочие \\
\hline \multirow{2}{*}{ A, Ж } & \multirow{2}{*}{1,42} & 57,63 & - & 42,37 \\
\hline & & 51,93 & - & 48,07 \\
\hline \multirow{2}{*}{ Б, К } & \multirow{2}{*}{7,2} & 89,93 & 10,07 & - \\
\hline & & 89,11 & 10,89 & - \\
\hline$\Gamma$ & 39,92 & 98,99 & 1,01 & - \\
\hline
\end{tabular}

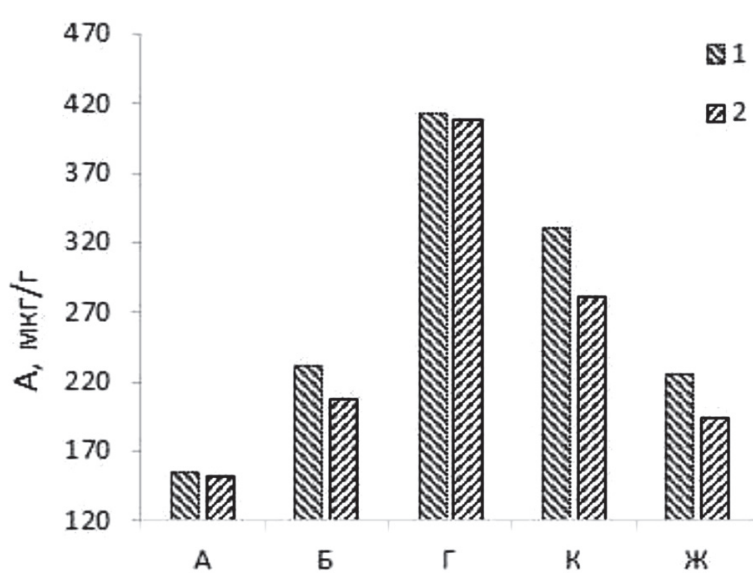

Рис. 1. Сорбция при скоростях:

$$
0,5 \text { (1) и 1,0 (2) мл/мин }
$$

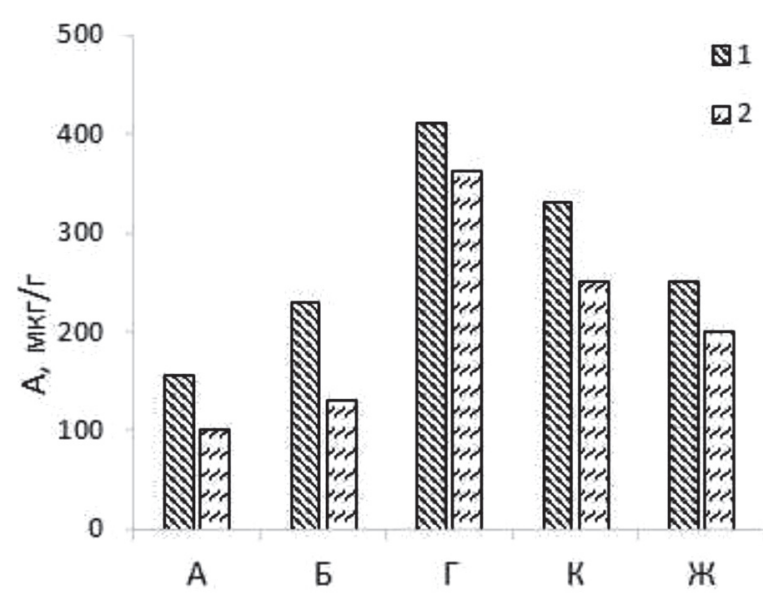

Рис. 2. Сорбция при размерах частищ: 0,375 (1) $и 0,75$ (2) мм

Ситовым анализом определено, что для мелкозернистого песка Г характерен небольшой диапазон 
размеров, остальные пески имеют иной гранулометрический состав (табл. 2).

Таблиия 2

Характеристика максимума на кривых распределения

\begin{tabular}{lccccc}
\hline \multicolumn{1}{c}{ Пески } & А & Б & \multicolumn{1}{c}{ Г } & К & Ж \\
\hline Размер, м & 0,375 & 0,375 & 0,185 & 0,750 & 0,750 \\
Доля, \% & 43,3 & 46,6 & 73,4 & 35,9 & 38,4 \\
\hline
\end{tabular}

При рассмотрении образцов из фракций с характерным для данного песка размером (по максимуму на кривых распределения) повышение скорости фильтрации приводит к снижению способности песка сорбировать ион $\mathrm{Fe}(\mathrm{III})$. При одинаковой скорости фильтрации такой же результат наблюдается с ростом пористости песка.

Как известно, для протекания поверхностного явления необходимы благоприятные предпосылки [17]. Структура поверхности песчинок определяется морфологией и кристаллохимическими особенностями обнаруженных в составе песков минералов, которые относятся к островным (оливин), слоистым (мусковит, клинохлор), каркасным или цепочечным (альбит, микроклин, плагиоклаз, амфиболы). Значимыми в составе песков А и Ж являются слоистые минералы, по природе хорошие адсорбенты [1, 18-20]. Однако пески являются примерами многокомпонентных минеральных образований, структура поверхности песчинок является совокупной характеристикой и отражает не только свойства слоистых минералов [21]. Поэтому можно предположить, что разнообразие минерального состава песков обеспечивает такие особенности поверхности минеральных частиц, которые оказываются подходящими для сорбции ионов железа. Указанное разнообразие минерального состава приводит и к различным количественным показателям сорбции.

\section{Выводы}

1. Пески прибрежных зон Северного и Центрального Вьетнама могут быть выделены втри группы - чистый кварцевый песок, кремне-глиноземистые и полиминеральные пески.

2. Барьерные качествапесков по отношению к ионам железа (III) связаны с геохимическими особенностями горных пород, выделенных в указанные группы.

3. Повышение скорости фильтрования и пористости минеральных композиций приводят к снижению сорбционной способности песков.

\section{Литература}

1. Везенцев А.И., Перистый В.А., Буханов В.Д., Перистая Л.Ф., Соколовский П.В., Ресснер Ф., Михайлюкова М.О., Грейш А.А. Журнал физической химии. 2018. Т. 92. №9. С. 1478-1485. DOI: 10.1134/ S0044453718090339.

2. Евсеев Н.В., Тютрин А.А., Пастухов М.П. Вестн. Иркут.гос. тех. университета. 2019. Т. 23. №4. C. 805-815. DOI: 10.21285/1814-3520-2019-4-805815 .

3. Berg M., Trang P.T.K., Stengel C., Buschmann J., Viet P.H., Van Dan N., Giger W., Stüben D. Chem. Geol. 2008. V. 249. N 1-2. P. 91-112. DOI: 10.1016/j.chemgeo.2007.12.007.

4. Гриневич В.И., Дунаев А.М., Румянщев И.В. Изв. вузов. Химия и хим. Технология. 2015. Т. 58. №2. C. $77-81$.

5. Буйнова С.А., Бубнов А.Г., Царев Ю.В., Семенов A.О. Изв. вузов. Химия и хим. технология.2019. Т. 6. №62. С. 119-130. DOI: 10.6060/ivkkt.20196206.5816

6. Рахманин Ю.А. Гигиена и санитария. 2016. Т. 95. N8. C. 701-707. DOI: 10.18821/0016-9900-201695-8.

7. Никашина В.A. Сорбционные и хроматографические процессы. 201. Т. 19. №3. С. 289-304. DOI: 10.17308/sorpchrom.2019.19/746.

8. Яковлева А.А., Аничиферов Е.А., Гусева Е.А., Садловский С.В. Известия вузов. Прикладная химия и биотехнология. 2019. Т. 9. №4. С. 600-611. DOI: 10.21285/2227-2925-2019-9-4-600-611

9. Питьевая вода. Гигиенические требования к качеству воды централизованных систем питьевого водоснабжения. СанПиН2.1.4.1074-01, утвержденные Главным государственным санитарным врачом Российской Федерации 26 сентября 2001 г., с 1 января 2002 года. Г.Г. Онищенко.

10. Нгуен Т.Ч., Яковлева А.А. Пески Вьетнама как объект коллоидно-химических исследований. Тез.матер. I всеросс. научно-техн. конф. «Проблемы земной цивилизации». Иркутск: Изд-во ИРНИТУ. 2018. Вып. 1. С. 22-27.

11. Коузов П.А. Основы анализа дисперсного состава промышленных пылей и измельченных материалов; 3-е изд., перераб. Л.: Химия, 1987. 264 с.

12. Яковлева A.А. Коллоидная химия. Учебное пособие. Изд-во: Юрайт. 2017. 209 с.

13. Беленький Д., Балаханов Д., Лесников Е. Аналитика. 2017. Т. 34. №3. С. 82-89. DOI: 10.22184/2227572Х.2017.34.3.82.89.

14. Методика измерений массовой концентрации общего железа в питьевых, поверхностных и сточных водах фотометрическим методом с сульфосалициловой кислотой. ПНД Ф 14.1:2:4.50-96 ФР 1.31.2013.16018.

15. Годовиков А.А. О связи свойств элементов со структурой и свойствами минералов. М.: Наука, 1989. $118 \mathrm{c}$.

16. Урусов В.С., Еремин Н.Н. Атомистическое компьютерное моделирование структуры и свойств неор- 
ганических кристаллов и минералов, их дефектов и твердых растворов. М.: ГЕОС. 2012. 428 с.

17. Цивадзе А.Ю. Структурная самоорганизация в растворах и на границе раздела фаз. М.: ЛКИ. 2008. $544 \mathrm{c}$.

18. Альсавальха М., Обра Е., Ресснер Ф. Исследование структуры природных монтмориллонитов. Сорбционные и хроматографические процессы. 2016. Т. 16. № 6. С. 781-787.

19. Полещук И.Н., Пинигина И.А., Созыкина Е.С. Со- временные наукоемкие технологии. 2019. Т. 1. №3 C. 65-69.

20. Нефедьева Т.А., Калюкова Е.Н., Благовещенская H.B. Сорбционные и хроматографические процессы. 2018. Т. 17. №3. С. 429-435. DOI:10.17308/ sorpchrom.2017.17/397.

21. Никифоров А.Ф., Кутергин А.С., Низамова А.Ф., Фоминых И.М., Трифонов К.И. Водное хозяйство России: проблемы, технологии, управление. 2018. №2. С. 92-109. 